\title{
Pró-PET-Saúde/Rede Urgência e Emergência: um Relato de Experiência Prática de Ensino-Serviço- Aprendizagem
}

\section{Pró-PET-Saúde/Urgency and Emergency Service: a Case Report on Field Experience within a Teaching-Service-Learning Process}

Isadora da Cunha Leite Andréa Silvia Walter de Aguiar Márcia Maria Pinheiro Dantas ${ }^{I I}$

\section{PALAVRAS-CHAVE}

- Fisioterapia;

- Saúde Coletiva;

- Educação em Saúde;

- Prática Profissional.

\section{KEYWORDS}

- Physiotherapy;

- Public Health;

- Health Education;

- Professional Practice.

RESUMO

Objetivo: Este estudo objetiva relatar a experiência da acadêmica do curso de Fisioterapia e extensionista do Pró-PET-Saúde da Universidade Federal do Ceará no Instituto Dr. José Frota de Fortaleza. Metodologia: Trata-se de um relato de experiência de abordagem qualitativa, com descrição de visitas supervisionadas, realizadas pela extensionista do Pró-PET-Saúde da Universidade Federal do Ceará no Instituto Dr. José Frota de Fortaleza durante 26 meses. Resultados: Foi vivenciada a rotina hospitalar de diversos profissionais da saúde na unidade concedente. Os procedimentos realizados eram efetuados pelo preceptor/profissional, e o aluno o observava, correlacionando os conhecimentos teóricos adquiridos com a prática visualizada. Conclusões: Nesse processo de vivência hospitalar, a visão inter-e multidisciplinar é abordada de maneira a beneficiar a formação acadêmica e de saudável convivência, expondo o aluno a inúmeras situações necessárias e benéficas. Observou-se a importância da inserção da fisioterapia na equipe profissional, auxiliando na reabilitação, bem-estar e melhora da qualidade de vida desses indivíduos.

\section{ABSTRACT}

Objectives: This study aims to report the experience of a Physical Therapy graduate from the Federal University of Ceará working as part of the Pro-PET Saude program in the Dr. José Frota Institute (JFI). Methodology: This is a case report with a qualitative approach, using descriptive data from supervised visits to JFI. Results: By staying in a certain hospital unit, the graduate was able to experience the routine of the health care professionals, observe how several procedures were executed and then correlate to previously acquired knowledge and visual practice. Conclusions: In this process of experiencing a hospital routine, multi and interprofessional practice is approached in a way to benefit the academic training process and the building of a healthy coexistence between professionals by exposing graduates to several routine and positive situations. Insertion of Physical Therapy was seen as important within a health care group since these professionals are able to assist in rehabilitation, thus improving the patients' quality of life. 


\section{INTRODUÇÃO}

O Programa de Educação Tutorial (PET-Saúde), instituído pela Lei ${ }^{\circ} 11.180$, de 23 de setembro de 2005, constitui um instrumento para viabilizar programas de aperfeiçoamento e especialização em serviço dos profissionais de saúde, bem como a iniciação ao trabalho, de acordo com as necessidades do Sistema Único de Saúde (SUS) ${ }^{1}$.

O programa tem como pressuposto a articulação entre ensino-serviço-comunidade e disponibiliza bolsas de educação pelo trabalho para tutores (vínculo direto com a instituição de ensino), preceptores (profissionais do serviço) e acadêmicos da saúde ${ }^{2}$, estimulando a formação de profissionais e docentes com elevada qualificação técnica, cientifica, tecnológica e acadêmica, bem como favorecendo a iniciação científica pautada pelo espírito da indissociabilidade entre ensino, pesquisa e extensão ${ }^{3}$.

Essa articulação favorece que a academia integre, durante todo o processo de ensino-aprendizagem, a orientação teórica com as práticas de atenção nos serviços públicos de saúde. Ela deve representar um novo padrão de prática que demanda uma orientação da formação em sintonia com as reais necessidades dos usuários do SUS, de modo a oferecer uma abordagem integral do processo de saúde-doença ${ }^{4}$.

Como apoio adicional, o Programa Nacional de Reorientação Profissional em Saúde (Pró-Saúde) foi instituído pela Portaria Interministerial $\mathrm{n}^{\circ} 2.101$, de 3 de novembro de 2005. Proposto pelo governo federal e coordenado pelos ministérios da Saúde e da Educação, tem como objetivo a integração entre ensino e serviço, contemplando a reorientação da formação profissional, de forma a assegurar uma abordagem integral do processo saúde-doença com ênfase na Atenção Básica, priorizando a equipe da Saúde da Família: Medicina, Enfermagem e Odontologia 5 .

Promovendo transformações na prestação de serviços à população já existentes e favorecendo o aprimoramento do trabalho colaborativo, o Pró-Saúde compreende três eixos: orientação teórica, cenários de prática e orientação pedagógica. Espera-se que a articulação entre as instituições de ensino superior e o serviço público de saúde potencialize as respostas às necessidades da população com vistas ao fortalecimento do SUS6.

O Programa Nacional de Reorientação da Formação Profissional em Saúde (Pró-Saúde), articulado ao Programa de Educação pelo Trabalho para a Saúde (PET-Saúde), em parceria com a Universidade Federal do Ceará (UFC), é constituído por cinco eixos temáticos: urgência e emergência, saúde da família, vigilância à saúde, rede cegonha e atenção psicossocial.
As redes de atenção à saúde são consideradas uma nova forma de organizar o sistema de atenção á saúde em sistemas integrados cujo propósito primário é promover, restaurar e manter a saúde de uma população ${ }^{7}$. Tais redes permitem responder, com efetividade, eficiência, segurança, qualidade e equidade, às condições de saúde da população usuária, garantindo uma proteção adequada dos riscos ${ }^{8}$.

Em 2011, o PET-Saúde da Universidade Federal do Ceará incorporou um novo eixo, denominado urgência e emergência, no maior hospital de emergência do Estado do Ceará. Foi um desafio, tendo em vista a magnitude do hospital e os processos de trabalhos lá existentes, como atividades em regime de plantão. O PET-Saúde/UFC passou a executar atividades no Instituto Dr. José Frota (IJF). Trata-se de uma instituição da rede pública de saúde que presta serviço de pronto-socorro a pacientes traumatizados e que atualmente é o maior hospital terciário de urgência e emergência do estado. O IJF promove a reabilitação no contexto biopsicossocial, e para isto é necessária uma atuação multidisciplinar?.

Este estudo tem como objetivo relatar a experiência vivenciada por uma acadêmica do curso de graduação em Fisioterapia da Universidade Federal do Ceará, bolsista-participante do projeto de extensão Pró-PET-Saúde/Rede Urgência e Emergência da UFC no Instituto Dr. José Frota, situado no município de Fortaleza (CE).

\section{METODOLOGIA}

Trata-se de um relato de experiência de caráter descritivo, que utiliza o método de observação incorporada, com uma abordagem qualitativa das atividades desenvolvidas entre outubro de 2012 e dezembro de 2014, por uma discente do curso de Fisioterapia, extensionista-bolsista do PET-Saúde/UFC Rede Urgências e Emergências, contendo descrições de visitas supervisionadas, bem como contribuições e influências do programa na formação educacional da acadêmica.

O Pró-PET-Saúde utiliza uma metodologia ativa no processo de ensino-aprendizado, composta por vivência da prática com profissionais/preceptores do serviço; reflexão e discussão da prática vivenciada; discussões/mesa-redonda de casos clínicos vivenciados; capacitações com abordagem dos temas pertinentes à prática.

Conforme a proposta, a discente passou a acompanhar as atividades hospitalares do Instituto Dr. José Frota durante 26 meses, com carga horária semanal de 12 horas, distribuídas em quatro horas para o planejamento e avaliação das atividades e reuniões com tutores e preceptores; e oito horas de atividades realizadas nos cenários de prática. 


\section{RESULTADOS E DISCUSSÃO}

De início, houve encontros para a realização de capacitações multiprofissionais dos acadêmicos. O preceptor ministrava aulas e distribuía material didático sobre os temas pertinentes. Os acadêmicos também apresentavam seminários com temas diversos, inicialmente identificados como problematizadores do ensino-aprendizado. Isto foi essencial para o aprofundamento sobre a instituição, principais ações, protocolos e serviços oferecidos.

Também foram realizadas atividades sociais e dinâmicas entre os bolsistas monitores juntamente com os preceptores, por meio de encontros mensais nos quais os integrantes conheciam uns aos outros, beneficiando, assim, o conhecimento adquirido e proporcionando uma troca positiva de experiências.

Foi vivenciada a rotina hospitalar de diversos profissionais da saúde que trabalham na unidade concedente. Os procedimentos realizados eram efetuados pelo preceptor/ profissional, e o aluno os observava, correlacionando os conhecimentos teóricos adquiridos com a prática visualizada momento único e de interdisciplinaridade proposto pelo Pró-PET-Saúde, que gerou grande contribuição para a formação profissional.

Esse momento foi essencial para que, com base nos problemas encontrados, fossem planejadas ações preventivas, promocionais, curativas e atividades educacionais, mostrando que os extensionistas são excelentes multiplicadores de conhecimento e boas ações. Podemos observar que as ações contribuíram de forma positiva para todos os envolvidos, trazendo novos conhecimentos e noções do funcionamento hospitalar.

Posteriormente, as ações foram direcionadas ao atendimento hospitalar de terapia intensiva, executado pelo próprio acadêmico, com supervisão contínua do preceptor. Foram realizadas atividades como avaliação clínica e funcional, protocolos de reabilitação, leitura de exames complementares e exercícios manuais e respiratórios. Essas atividades contribuíram de forma expressiva para o aperfeiçoamento da extensionista, que foi levada a práticas fisioterápicas fora do ambiente universitário.

Os alunos extensionistas, além de desenvolverem as atividades práticas e elaborarem material didático, também produziram cientificamente de acordo com o seu campo de atuação, respeitando as atribuições e diretrizes do programa.

Seguindo para a diretriz da pesquisa, a extensionista elaborou o projeto de pesquisa "Perfil epidemiológico de pacientes vítimas de queimaduras de terceiro grau assistidos pela fisioterapia internados em um hospital público municipal", que foi aprovado pelo Comitê de Ética em Pesquisas em Se- res Humanos. Todos os resultados obtidos foram apresentados em encontros científicos da UFC. Mais tarde, o projeto se tornaria uma extensão do trabalho de conclusão do curso de graduação em Fisioterapia.

A contribuição do Pró-PET-Saúde na formação acadêmica proporcionou a compreensão das diretrizes curriculares voltadas às políticas de saúde, o reconhecimento da importância da participação da fisioterapia nas equipes multidisciplinares, a compreensão do papel do fisioterapeuta no âmbito hospitalar, o conhecimento da dinâmica do trabalho em equipe, entendendo a interdependência positiva existente, o entendimento da necessidade da interdisciplinaridade nas redes de saúde, o conhecimento da epidemiologia regional e da contribuição do profissional para o desenvolvimento das possibilidades do SUS.

\section{CONCLUSÃO}

Nesse processo de vivência hospitalar, a visão inter- e multidisciplinar é abordada de maneira a beneficiar a formação acadêmica e de saudável convivência. $\mathrm{O}$ aluno é exposto a inúmeras situações necessárias e benéficas por meio da troca de experiências e conhecimentos entre acadêmicos, preceptores e tutores, percebendo, assim, a importância do ensino de práticas para os acadêmicos da área de saúde.

Acreditamos que projetos como este estimulam a formação diferenciada de novos profissionais da área, abrangendo não só as mudanças na formação curricular, como também uma reflexão sobre o processo de trabalho em saúde.

Observou-se ainda a importância da inserção da fisioterapia na equipe profissional, apresentando colaboração significativa no cuidado ao paciente, auxiliando na reabilitação, bem-estar e melhora da qualidade de vida do indivíduo.

\section{AGRADECIMENTOS}

Os autores agradecem o apoio dos ministérios da Educação e da Saúde por meio da concessão de bolsas. Aos profissionais, pela disposição e compreensão. Aos pacientes, pela paciência, colaboração e confiança depositada em nós. Aos demais acadêmicos, preceptores e professores, pela troca de experiências e pela contribuição científica. Ao Instituto Dr. José Frota, pela disposição, disponibilidade, acolhimento e concessão de espaço para a operacionalização e realização do programa.

\section{REFERÊNCIAS}

1. Brasil. Ministério da Saúde.Ministério da Educação. Portaria Interministerial $\mathrm{n}^{\circ} 1.802$, de 26 de agosto de 2008. Instituir o Programa de Educação pelo Trabalho para a Saúde (PET-Saúde). Diário Oficial da União. Brasília, 26 ago. 2008; Seção 1, p. 27. 
2. Padilha JF, Porolnik S, Gasparetto A, Mattos KM, Miolo SB. O PET- SAÚDE na formação de acadêmicas do curso de fisioterapia: um relato de experiência. II Fórum de Integração em Fisioterapia Unificando Ações em Prol da Saúde. II Fórum de Integração em Fisioterapia Saúde e Integralidade Entre os Diferentes Profissionais da Área da Saúde; 2011 ago-set. 31-02. Rio Grande do Sul, Brasil.

3. Brasil. Ministério da Saúde. Ministério da Educação. Portaria Interministerial $n^{\circ}$ 422, de 03 de março de 2010. Institui o Programa de Educação pelo Trabalho para a Saúde (PET-Saúde) e dá outras providências. Diário Oficial da União. Brasília, 05 mar. 2010; Seção 1, p. 53.

4. Brasil. Ministério da Educação. Ministério da Saúde. Programa Nacional de Reorientação da Formação Profissional em Saúde - Pró-Saúde. Brasília; 2007.

5. Brasil. Ministério da Saúde. Ministério da Saúde. Portaria Interministerial $n^{\circ}$ 2.101, de 03 de novembro de 2005. Institui o Programa Nacional de Reorientação da Formação Profissional em Saúde - Pró-Saúde: para os cursos de graduação em Medicina, Enfermagem e Odontologia. Diário Oficial da União. Brasília, 04 nov. 2005; seção 1, p. 111.

6. Brasil. Ministério da Saúde. Portaria $\mathrm{n}^{\mathrm{o}}$ 1.996, de 20 de agosto de 2007. Dispõe sobre as diretrizes para a implementação da Política Nacional de Educação Permanente em Saúde e dá outras providências. Diário Oficial da União. Brasília, 22 ago. 2006; Seção 1.
7. Mendes EV. As redes de atenção à saúde. Brasília: Organização Pan-Americana; 2011.

8. Mendes EV. Revisão bibliográfica sobre redes de atenção à saúde. Belo Horizonte: Secretaria de Estado de Saúde de Minas Gerais; 2007. (Relatório)

9. Instituto Doutor José Frota. Disponível em: http://www. fortaleza.ce.gov.br/ijf/historico. Acessado em: 01 mai. 2015.

\section{CONTRIBUIÇÃO DOS AUTORES}

Isadora da Cunha Leite participou da redação do artigo. Andréa Silvia Walter de Aguiar e Márcia Maria Pinheiro Dantas colaboraram na análise, redação do artigo e aprovação final da versão a ser publicada.

\section{CONFLITO DE INTERESSES}

Nenhum dos autores deste estudo relata conflito de interesses.

\section{ENDEREÇO PARA CORRESPONDÊNCIA}

Isadora da Cunha Leite

Av. Cesar Cals, s/n ${ }^{\circ}$

Alto São Francisco - Trairi

CEP 62690-000 - CE

E-mail: isadoracunhaleite@gmail.com 